\title{
HUMAN INFORMATION INFRASTRUCTURE AND ADMINISTRATIVE EFFICIENCY (HIIAE) OF SELECTED ENTERPRISES IN THE CIVIL AVIATION INDUSTRY IN THE SOUTH-SOUTH, NIGERIA
}

\author{
Dr. (Mrs). Bestman, Anthonia \\ Department of Office and Information Management, \\ Faculty of Management Sciences, \\ Rivers State University, Port Harcourt, Nigeria.
}

\begin{abstract}
This paper examined how human infrastructure impacts on administration efficiency of aviation industry in Nigeria. In line with the purpose of this paper as stated, population of this study comprises of 80 senior and junior staff of the various ICT departments of four Airports operating in the South-South of Nigeria. The Taro-Yamene sample size determination formula was used to determine the sample size. The objective of this study is to assess the relationship between human infrastructure impacts on administration efficiency of aviation industry. Questionnaires were the major instruments used in gathering primary data which were analyzed using regression analyses. The study found that aviation industry can achieve improvement along the terms of administration efficiency if the aviation industry is able to improve on their products and deliver on their service more effectively and efficiently base on the findings, we recommends that in order for firms to maintain their attractiveness in the industry, they must have be conscious what modern technology is available in the industry and apply same on their own business as this will help the in expanding their market coverage with different products.
\end{abstract}

KEYWORDS: human, infrastructure, administration, efficiency, innovation, service delivery.

\section{INTRODUCTION}

Today administrative works in our enterprises have changed generally. On this basis, it has become necessary to provide tools that can do administrative work processes quickly and accurately and respond to them on time (Fatemeh M, 2012). This has led to the automation of enterprise systems as an innovative method which on the one hand accelerates the work processes, and the other hand has been able to centralize, classify and collect data and provide appropriate platform for the day to day tasks. It is hence, imperative to state here that enterprises can only be sustainable if they consciously rely on Information Infrastructure networks for the conduct of their vital operations. That is to say that information technology has now moved further away from the usual independent personal computing (PC) age, when enterprise computer systems barely connect to the internet to rather an era of integration of large scale networks of enterprise computing perpetually through the web.

It is of note that IT infrastructure is the shared technology resources that provide the platform for the enterprise specific information system applications to thrive. IT infrastructure includes hardware, software, and services that are shared across the entire organization. Major IT infrastructure components include computer hardware platforms, operating system platforms, enterprise software platforms, networking and telecommunications platforms, database management software, Internet platforms. The digital convergence enabled by the integration 
character of IT Infrastructure has resulted in increasingly complex amalgams of organizational arrangements that make up organizational life (Hanseth \& Ciborra, 2007; Hanseth \& Lyytinen, 2010; Tilson et al., 2010).

The speed of technological evolution from Information Technology into information super infrastructure came through five generations as follows: the mainframe era, the personal computer era, the client/server era, the enterprise computing era, and the cloud and mobile computing era (infrastructure). Bygstad (2010) argues that the notion of information infrastructure, as opposed to the traditional "information system", offers two distinct advantages. First, it changes the object of study from a single, stand-alone, application within an organization to large scale socio-technical networks of interrelated technical and social entities. Second, it offers a new perspective on how such networks are developed and evolve which brings to attention the conceptual components for the study. This research work is primarily aimed to investigate the changing face of human infrastructure that has exited the era of personal computer (pc) or stand-alone office systems, awaiting the full moon of interconnected array of computer sets, software of all information and communication technologies supported by the internet; that links the enterprises to global reach of all people and business facilities in Nigeria and Africa respectively. The purpose of this study is to determine how human infrastructure impact on administrative efficiency of Selected enterprises in the civil aviation industry in the south-south, Nigeria. The objectives are to determine:

- To determine how human infrastructure deepens service delivery in the civil aviation industry in the South-South of Nigeria.

- To determine how human infrastructure deepens innovation in the civil aviation industry in the South-South of Nigeria.

Two researchable questions were raised, they include:

- To what extent does a human infrastructure support service delivery in the civil aviation industry in the South-South of Nigeria?

- To what extent human infrastructure supports innovation in the civil aviation industry in the South-South of Nigeria?

In carrying out the study, two research hypotheses were stated, which include:

Ho1: There is no significant relationship between human infrastructure and innovation in the civil aviation industry in the South-South of Nigeria.

Ho2: There is no significant relationship between human infrastructure and service delivery in the civil aviation industry in the South-South of Nigeria 


\section{Conceptual framework}

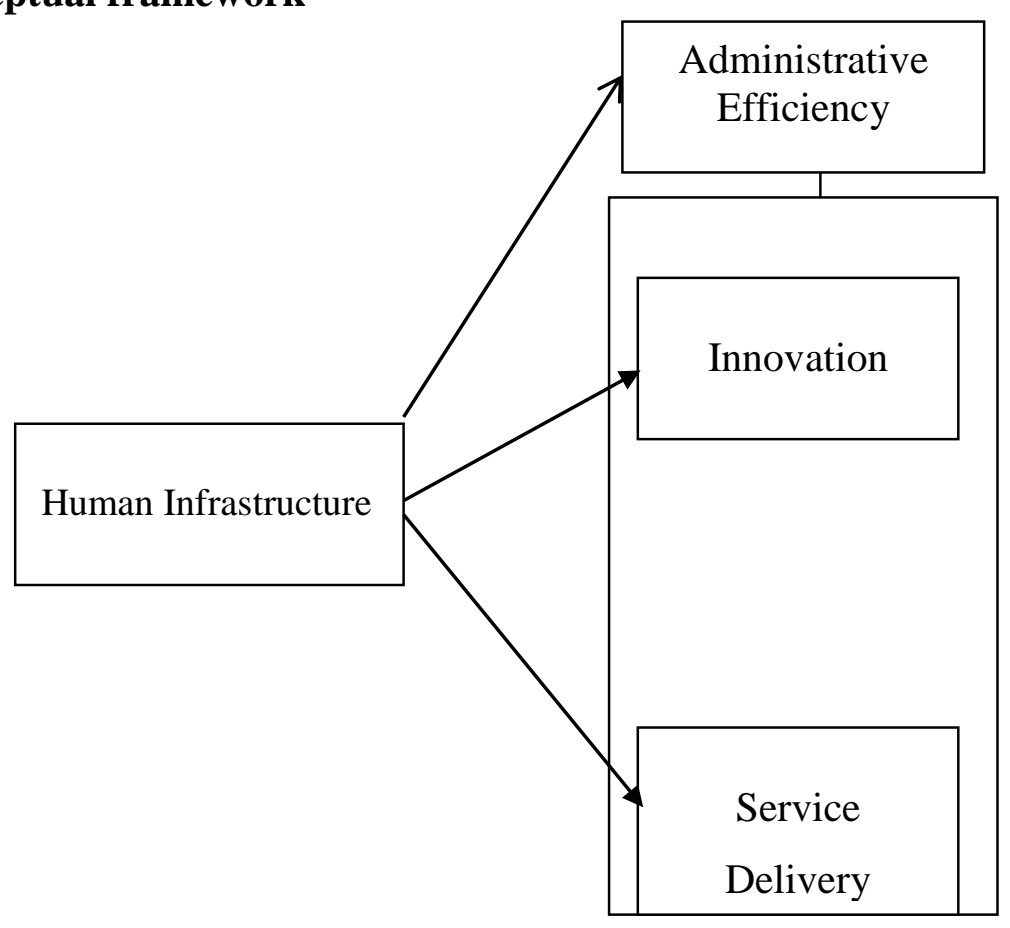

Conceptual Framework on Human Infrastructure and Administrative Efficiency of some Selected Enterprises in the Civil Aviation Industry In The South-South, Nigeria

\section{THEORETICAL FOUNDATION}

Theoretical foundation is an explanation based on ideas that are related to a particular subject. It is a critical review of the theoretical elements that serve as a frame of reference in an investigation. This critical review allows us to determine the variables to be measured and the relationship between them, while determining the response to the research question. In our effort to search and conceptualize how human infrastructure stimulates administrative efficiency of some selected enterprises in the civil aviation industry in the south-south, Nigeria. In order to clarify the important of human infrastructure in the aviation industry a theory has been raised to help explain more on the issue of discussed. This study looks at actor network theory that is applicable in all firms.

The researcher thinks Actor network theory (ANT) simply provides the analytical framework for dissecting the facts associated with global information infrastructure as the supportive base for enterprise information infrastructure thrive. This study therefore reams with the theoretical framework of ANT which was established, expanded, and reexamined by social scientists and sociologists (Callon, 1986; Fenwick \& Edwards 2010, Sayes 2014). The Actor-Network Theory refers to at least two or multiple entities which mutually affect each other, either directly or indirectly. The focus is on how different elements form and shape each other to form a whole. It is a relationship often treated as an act of translation between elements or forces. A Translation that looks into how individual artifacts, interact, whether they connect with one another to formulate networks, and how these things shift through their interconnection (Fenwick \& Edwards, 2010). 
The Actor-Network Theory is actually broken down using three conceptual phrases: "the Actor-World, the Translation, and the Actor-network. The Actor-World here describes the interoperability protocols within the machine to machine processes started by the user as the information Infrastructure world. While Translation provides the processes taken for interrelation of different users actions working with the machines actions all converted at this stage to computer language in the actor world. And so the actor-network is the outcome these actions translated to showing the varieties of dynamic and colourful inter connectivity in the actor-world in a collocated way.

ANT deals with the social-technical divide by denying that it is purely technical or purely social relations, debunking the dichotomy between the social and the natural, the cultural and the material through a close examination into material things or non-human actors (Fenwick \& Edwards, 2010). That the underlying assumption of ANT is that social communicative actions "involve both people and technologies, and that the material features of a technology are developed and used in a system of social relationships" (Contractor, Monge, \& Leonardi, 2011).

That is to say, ANT resists a predefined distinction between human systems and material entities with the idea of ANT following the three interconnected notions, i.e., "translation", or how things change each other to form connections; "network assemblage", or how things are held together in networks; and "symmetry", or how things exert equal forces as human beings do (Fenwick \& Edwards, 2010). And so, this work emphasis the interconnection and interplay as the main dynamics that shapes and defines the new state of information infrastructure for the enterprise. The relational dimension of information infrastructure which is studied as the outcome of the existing intricacy and interdependences among various technologies and applications (Hanseth, 2004) has resulted in organizational agents adopting and using these technologies and applications inter-reliantly.

\section{Human Infrastructure}

The first real descriptions of Information infrastructure never focused on humans as part of the technology components of IT infrastructure (e.g. Earl 1989, Turnbull 1991). Despite the fact that the human component of IT Infrastructure was known and should have being recognized (Mckay and others 1989), it was indeed not until the mid-1990s that it was actually emphasized. Broadbent, et al., (1996) emphasized the necessity of human component of IT infrastructure in providing the planning, design, construction and operational capability need for viable IT infrastructure. And that the human IT infrastructure binds the IT components into a reliable set of shared IT Infrastructure services.

Human Infrastructure here refers to the large number of people in IT businesses and professionals who develop applications and services for the creation of information in the enterprise and the IT environment. Human information infrastructure includes the knowledge, skills, policies, standards and experiences required for building the technology components to the necessary services required Mckay and Brockway (1989).

In all it is human infrastructure flexibility that lends information infrastructure the strength and allows it meet demands quickly. Humans and Information processing technology have reached 
a very high creative collaboration level such as artificial intelligence, sensor technology, network technology, simulation, robotics, human-machine interface etc. to solving the organizational problem. Hence, in the last few years studies have shown the changes in society and human behavioural patterns in the use of Information Infrastructure in homes and enterprise environments in the USA, South East Asia (Singapore, Malaysia) and Japan. The trend is that the homes and organizations are moving towards encompassing virtual space as they do with physical space with the driving forces from converging and embedded technologies in the internet (Bradley, Linda et al 2000, Bradley, L. and Bradley, G. 2001, Bradley L. 2005, Danielsson 2007).

In conclusion, the use of Information Infrastructures have changed the human qualities from self-identity and self-perception to social competence; creativity; integrity; dependency, and vulnerability of distance which have brought importance balance to society. Again, in as much as IT infrastructure cannot exist without regular operations and maintenance supports, humans will continue to operate maintain and monitor the numerous IT infrastructure technologies as much as it is fulfilling their tasks; storage, processes, and business support systems (McDonald and Aron, 2011).

\section{Administrative Efficiency}

The word administration has become so common in use such that it's meaning and concept is swept under the carpet. This is because there is now innumerable ways by which the word is being used such that its meaning seem to associate on the context it is used in. According to Oxford English Dictionary (2010) Administration is the process or activity of running a business, organization, etc. In this paper, the researcher describes administration to mean the process or activity of running an enterprise, specifically with the aid of information infrastructure. Practically, everyone in an enterprise undertakes in one administrative function or the other. Hence, Administration is regulated by rules; these can be all kinds of rules, formal or informal (Bider, 2008).

Efficiency is the ratio of the output to the input of any system (Oxford English Dictionary, 2010). Therefore, the working definition of Administrative Efficiency can be interpreted as the optimization of information infrastructure resources within a set of rules directed towards organizational goal in which case the aviation industry. By the very nature of the aviation industry, two measures have being conceptualized to investigate the relationship of administrative efficiency over human Infrastructure thus:

\section{Innovation}

Innovation can be described as the capacity of continuously achieving a desired information infrastructures future and changes that create both new and valuable technical competence in the organization. And there are indeed many recent advancements and changes in both the hardware and software technologies in the air transport industry. Some of the recent innovations which are increasing the efficiency and effectiveness in the administration of airport operations are as detailed below.

Social network analysis (SNA) is a powerful tool used for security management in airports to analyze, discover and envision the actions of criminal suspects. With SNA it is possible to map the relationship of a criminal elements. This is because the manual examination of social 
networks is time consuming and ineffectual compared to the use of SNA which accelerates the effectiveness and efficiency for airport security, traffic from data on telephones and email may represent an important clue to solving a criminal activity at the airport (Custers, 2012). Thus, to reduce criminal behavior, the use of SNAs by law enforcement agencies is essential in the context of having an effective crime fighting strategy in the industry (Johnson, Reitzel, Norwood, McCoy, Cummings, \& Tate, 2013).

Biometrics refers to technologies based on an individuals' unique characteristics, such as their finger prints, their DNA make up, and their voice patterns (Custers, 2012). The potential of biometrics in the air transport is gaining attraction across the industry. Biometrics are now used to identify individuals. The integration of biometric technology into consumer devices, such as the iPhones, androids, which features facial recognition technology is helping to keeping air travelers safe.

Speech recognition technology is also useful for security purposes to identify audio samples of criminals and to compare these with known criminal profiles (Findbiometrics, 2014). Biometric-enabled self-service check-in and bag drop facilities are now commonplace in airports around the world, biometrics technology looks set to play a crucial role in adding a further layer of security and creating a more seamless experience for the passenger in aviation industry.

The factors that make a society feel unsafe such as higher crime rates, increased terrorist attacks, and school and workplace shootings have led airport security agencies to install closedcircuit television (CCTV) security monitoring systems in many locations. Some of these video cameras are installed inside vehicles and are used to monitor stops and vehicular movement in the airport with the aid of information infrastructures. Information technology has created a new form of cultural banks for redefining the knowledge and skills required for efficient airport operations. The effective use of modern technological advancements is bringing innovative solutions in the aviation industry.

\section{Service Delivery}

Information Infrastructure has always had an inseparable affinity with every other technological system since the world moved from analogue to digital technology. Not only does information technology provides effectiveness and efficiency but it virtually controls almost all the technologies in an organization. It also enhances professional status and organizational legitimacy (Manning 1992a; Ericson and Haggerty 1997).Service Delivery in this case is described as the measurement of success rate enhanced by information infrastructure in the organization within a given period of time.

The two most supported functions by the information infrastructure in the aviation industry are the; airlines' flight operational activities and the business management and control functions. As far as operations are concerned, Information infrastructure contribute to the optimization of all flight related procedures and processes. Some of the airline operations supported by Information infrastructure includes dispatch and coordination of flights and related resources such as crew, aircraft, passengers and freight processing. Others are airport facilities such as gates, ramps, baggage handling etc. From a business management and control point of view, 
airlines employ information Infrastructure in most functions, from administrative tasks to financial management, human resources and procurement (Verville, 2003).

Information Infrastructure also brings together the main airport partners such as Air Traffic Control (ATC), airport operators, airlines, ground handlers etc. to share operational data. Such information sharing is fundamental to achieving a common situational awareness, which improves decision making (Aguado, 2009). It is an approach to optimizing resource usage and improving timeliness at an airport. It is all about partners at an airport working together, openly sharing accurate information together through the use of information infrastructure for the predictable airport operations smoothly. For an instance the turnaround operation of a single aircraft involves multiple actors with different roles, the Airport Collaborative Decision Making (A-CDM) information service provider, which operates a Message Broker Information Sharing Platform (MBISP) for exchanging information between the airlines, air traffic and ground handling service provides the;

- $\quad$ Airline, who operates the aircraft with the schedules of the inbound and outbound flights who ultimately pays for the turnaround services rendered.

- $\quad$ Air traffic management services allocate and manage the use of airspace including airport landing and take-off slots, provide information about inbound flights, and need predictions when an aircraft will be ready for outbound flights via information infrastructure.

The ground handling organization, which coordinates the provision of services to the aircraft is to make it ready for takeoff by providing ground handling services which includes aircraft cleaning, refueling, baggage unloading and loading, and catering etc. Information

Infrastructure also ensures that no baggage is transported without its owner, as per International Civil Aviation Organisation regulations. The systems support reconciliation procedures of checking passengers' baggage to enable airlines ensure security, reduce operating costs, and improve passenger satisfaction without compromising punctuality (M. Dell, C. Bunney, 2001).All actions involved in turning around an aircraft can be planned more accurately, and the plans can only be easily controlled from the various departments through the use information infrastructure.

The timeliness of airlines operations require accurate information and continuous monitoring for deviations or dangers as to enable countermeasures to be set proactively. The importance of information infrastructure to this sector cannot be overemphasized. By any means, is of massive benefits to airports and their customers alike.

In a nutshell, Enterprise information infrastructures are middleware systems residing between the systems for end users applications of which some are provided by service providers. They play the role of functional bridge to link the gap between application programs and the lowerlevel hardware and software infrastructure in order to coordinate how parts of applications or systems are connected and interoperate simultaneously. Indeed they the systems of all systems.

\section{METHODS}

The study used both descriptive and inferential statistical tools to analyze its data; the information collected from the questionnaire was summarized in their groups and percentage 
were used to analyses the data, also inferential statistical tool of regression analyses was used to test the level of significance among variables and finally The analysis was aided with SPSS version 21.0.

$\mathrm{Y}=\mathrm{F}[\mathrm{X} 1, \mathrm{X} 2, \mathrm{X} 3 \ldots \ldots . \mathrm{XN}]$

Where $\mathrm{Y}=$ dependent variable

$\mathrm{X} 1, \mathrm{x} 2, \mathrm{x} 3 \ldots \mathrm{xn}=$ independent variable

$\mathrm{F}=$ Functional relationship among variables

The study was conducted within the Port Harcourt metropolis where some avaition sectors have their offices in different parts of the city. Taro-Yamene sample size determination formula was used to determine the sample size

\section{Reliability of the Research Instrument}

The scale to use for this study had been previously adjudged reliable. However, we will verify reliability outcomes through confirmatory test of internal consistency on the instrument with our sample using Cronbach alpha. This calculates the average of all possible Split-half Reliability Coefficient and the threshold level, 0.7 which is generally accepted by the rule of thumb (Cortina, J. M. , 1993) will be considered adequate.

\section{FINDINGS}

\section{Result and Frequency Analysis}

In this section, the output of the primary and secondary data is presented. Analysis was carried out on individual variables and measures. Mean scores and standard deviations are also illustrated. The presentation begins with the independent variable which is human infrastructure. It then proceeds to the dependent variable- administrative efficiency, whose measures are innovation and service quality delivery. These are all scaled on the five (5) point Likert scale (ranging from 1: $\mathbf{S D}=$ =strongly disagree, 2: $\mathbf{D}=$ disagree, 3: $\mathbf{N}=$ neutral, 4: $\mathbf{A}=$ agree and 5: $\mathbf{S A}=$ strongly agree).

The secondary data analysis was carried out using the Spearman rank order correlation tool at a $95 \%$ confidence interval. Specifically, the tests cover hypotheses $\mathrm{HO}_{1}$ to $\mathrm{HO}_{2}$ which were bivariate and all stated in the null form. We have relied on the Spearman Rank (rho) statistic to undertake the analysis. The 0.05 significance level is adopted as criterion for the probability of either accepting the null hypotheses at $(p>0.05)$ or rejecting the null hypotheses at $(p<0.05)$

We had proposed three hypotheses in the introduction one and two of this study to seek explanation between human infrastructure and administrative efficiency. The Spearman rank order Correlation coefficient is calculated using the SPSS 21.0 version to establish the relationship among the empirical referents of the predictor variable and the measures of the criterion variable. We used this to answer research questions one to six. Correlation coefficient can range from -1.00 to +1.00 . The value of -1.00 represents a perfect negative correlation while the value of +1.00 represents a perfect positive correlation. A value of 0.00 represents a lack of correlation. In testing hypotheses one to three, the following rules were upheld in accepting or rejecting our alternate hypotheses: all the coefficient values that indicate levels of significance (or) as calculated using SPSS were accepted and therefore our alternate hypotheses rejected; when no significance is indicated in the coefficient $r$ value, we reject our alternate 
hypotheses. Our confidence interval was set at the 0.05 (two tailed) level of significance to test the statistical significance of the data in this study.

Table 1 Shows the mean(x), Standard Deviation and Rank Order Statistics on Research Question 1: To what extent Human Infrastructure supports Service Delivery in the selected Civil Aviation Enterprises in the South-South of Nigeria?

\begin{tabular}{|l|l|l|l|l|l|l|}
\hline Questionnaire Items & & & & & & \\
\hline $\begin{array}{l}\text { 1. } \\
\text { To what extent Human skills form integral part } \\
\text { of Information Infrastructure in your } \\
\text { organization? }\end{array}$ & 55 & 1 & 4 & 3.45 & 0.677 \\
\hline 2. & $\begin{array}{l}\text { To what extent Human skills are required operate } \\
\text { Information Infrastructure in your organization? }\end{array}$ & 55 & 1 & 4 & 3.28 & 0.816 \\
\hline 3. & $\begin{array}{l}\text { To what extent Human Infrastructure is the } \\
\text { reason for all other Information Infrastructure } \\
\text { creations and innovations? }\end{array}$ & 55 & 1 & 4 & 3.28 & 0.847 \\
\hline 4. & $\begin{array}{l}\text { To what extent Human Infrastructure expertise } \\
\text { and capabilities give your organization } \\
\text { competitive advantage? }\end{array}$ & 55 & 1 & 4 & 3.23 & 0.800 \\
\hline Valid N (listwise) & 55 & & & & \\
\hline
\end{tabular}

Source: Research survey, 2019.

Table1 shows a total of fifty five (55) respondents that answered the various questions on Human Infrastructure, the respondents rate ranges from 1 to 4 , of which 1 was the minimum and 4 the maximum on the Likert Scale, question one shows that Human skills form integral part of Information Infrastructure in the organization with a mean of 3.45 and a standard deviation of 0.677 , question two on Human skills are required to operate Information Infrastructure in your organization with a mean of 3.28 and standard deviation of 0.816 , question three also shows a positive response that; Human Infrastructure is the reason for all other Information Infrastructure creations and innovations with a mean of 3.28 and standard deviation of 0.847 and lastly question four shows that Human Infrastructure expertise and capabilities give the organization competitive advantage with a mean of 3.23 and standard deviation of 0.8000 . These results shows that Human Infrastructure is the centre of any Enterprise Information Infrastructure.

Table 2:Descriptive Statistics for Human Infrastructure

\begin{tabular}{llllll}
\hline & $\mathrm{N}$ & Minimum & Maximum & Mean & Std. Deviation \\
Human Infrastructure & 55 & 1.00 & 5.00 & 3.1240 & 1.36516 \\
Valid N (listwise) & 55 & & & & \\
\hline
\end{tabular}

SPSS 21.0 Data Output, 2019 
Table 2 above illustrates the descriptive statistics for human infrastructure with mean score 3.1240 and indicates that most of the respondents were on the moderate range of the measurement scale.

\section{Hypotheses Testing}

The following table shows the results of the hypotheses tested to validate the discussion of findings.

Table 3:Human Infrastructure and Innovation

\begin{tabular}{|c|c|c|c|}
\hline & & Human infrastructure & Innovation \\
\hline \multirow{3}{*}{$\begin{array}{l}\text { Human } \\
\text { Infrastructure }\end{array}$} & Pearson Correlation & 1 & $0.924 * *$ \\
\hline & Sig. (2-tailed) & & .000 \\
\hline & $\mathrm{N}$ & 55 & 55 \\
\hline \multirow{3}{*}{ Innovation } & Pearson Correlation & 0.924 & 1 \\
\hline & Sig. (2-tailed) & 0.000 & \\
\hline & $\mathrm{N}$ & 55 & 55 \\
\hline
\end{tabular}

Source: Research survey, 2019

Table 3 above shows a significant correlation at $\mathrm{r}=0.924$ where $\mathrm{P}$-value $=0.000(\mathrm{P}<0.01)$. This implies a strong and significant relationship between both variables at $95 \%$ level of confidence. We therefore reject the null hypothesis $\left(\mathrm{Ho}_{1}\right)$ and restate that there is a significant relationship between human infrastructure and innovation.

Table 4: Human Infrastructure and Service delivery

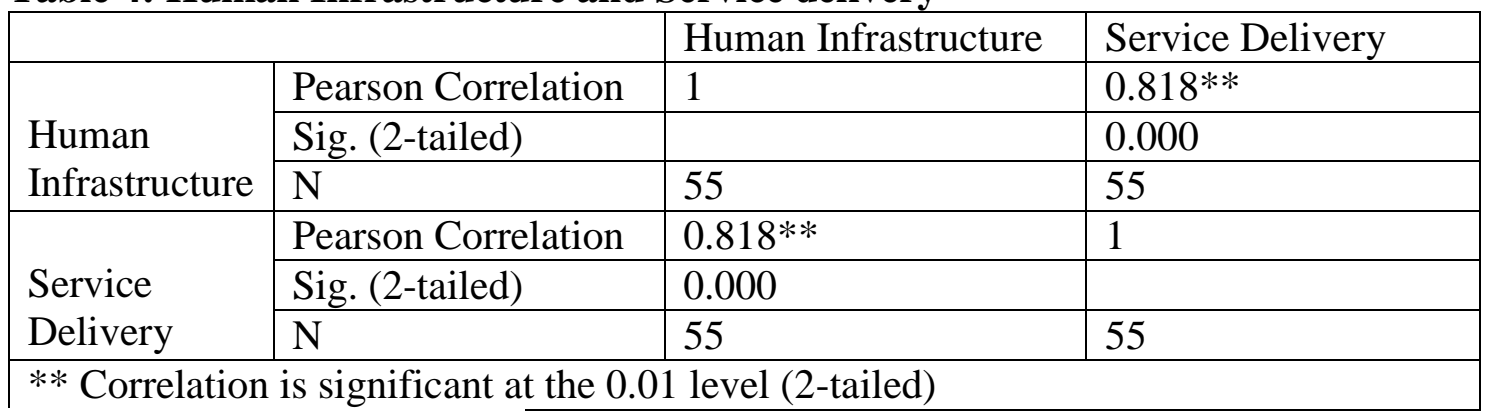

Source: Research survey, 2018

Table 4 above shows a significant correlation at $\mathrm{r}=0.818$ where $\mathrm{P}$-value $=0.000(\mathrm{P}<0.01)$. This implies a strong and significant relationship between both variables at $95 \%$ level of confidence. We therefore reject the null hypothesis $\left(\mathrm{Ho}_{2}\right)$ and restate that there is a significant relationship between human infrastructure and service delivery. 
Table 5: Descriptive Statistics for administrative efficiency

\begin{tabular}{llllll}
\hline & N & Minimum & Maximum & Mean & Std. Deviation \\
\hline innovation & 1211.00 & 5.00 & 3.0358 & 1.37423 \\
Service delivery & 1211.00 & 5.00 & 3.3829 & 1.32404 \\
Valid N (listwise) & 121 & & &
\end{tabular}

SPSS 21.0 data Output, 2019

Table 5 above illustrates the descriptive statistics for human infrastructure and administrative efficiency. Innovation with a mean score of 3.0358, service delivery with a mean score of 3.3829 indicates that most of the respondents were on the moderate range of the measurement scale.

Table 6: Descriptive Statistics for the study variables

\begin{tabular}{llllll}
\hline & $\mathrm{N}$ & Minimum & Maximum & Mean & Std. Deviation \\
\hline Human infrastructure & 55 & 1.00 & 5.00 & 3.1240 & 1.36516 \\
Administrative & 55 & 1.44 & 5.00 & 3.2507 & 1.22773 \\
efficiency & 55 & & & & \\
Valid N (listwise) & 55 & & & &
\end{tabular}

Source: SPSS 21.0 data Output, 2019

The data in table 6 illustrates the descriptive statistics summary for the study variables which are human infrastructure and administrative efficiency.

\section{CONCLUSION}

Clearly, the advent of the office information systems is over. The 21 st century offers a robust computerized telecommunications networks in the shape of Global Information Infrastructure as the foundational support of the human infrastructure in the Enterprise. It is therefore, imperative that to state that no business in this era can be sustainable without relying on the global human infrastructure networks for the conduct of their vital operations. The study concludes that all business strategies and developments must inculcate human infrastructure as the blood wire of its administration if it is to achieve its objectives and goal in today's global stage.

Based on the findings from the study; the study recommend that organization that wants to increase productivity should ensure that human Infrastructure is their focal point of interest especially in this jet age of information and communication technology. There should be proper monitoring and integration of information technologies innovations with human infrastructure so as to avoid being left behind by the rest of the world.

\section{REFERENCES}

Achterberg, J. S., van Es, G. A. \& Heng, M. S. H. (1991). Information systems research in the postmodern period'. information systems research: Contemporary approaches and emergent traditions. Nissen, H. E., Klein, H. K. and Hirschheim, R. (Eds). Elsevier 
Actor-Network Theory and Information Systems Research (PDF Download Available). Available from: https://www.researchgate.net/publication/228406931_Actor-Network Theory and Information Systems Research [Jan 13 2018].

Ahmad, (2012). The Moderating Effect of Technology Awareness: Centre for University Industry Collaboration, University Utara Malaysia.

Bider, S. (2018). Evaluating and Improving Quality of Administration. Retrieved March 11, 2012. From Ibissoft: http://www.ibissoft.se/whitepapers/admquality.pdf

Bradiley, G. (2005). The Convergence Theory on Information and Communication Technology (ICT) and the Psychosocial Life Environment. The Connected Home. Inc. G/ Salvendy, (Ed). Proceedings of the HCI International 2005 Conference, 22, 27 July 205, Las Vegas, Mahwah: Lawrence Erlbaum Associates.

Bradley, G. (Ed.) (2001). Human on the net. information of communication technology (ICT) work organisation and human beings. Stockholm: Prevent.

Bradley, L.. Andersson, N. \& Bradley, G. (2000). Home of the future - information and communication technology (ICT) - changes in society and human behavior patterns in the net era. FSCN Report R00-1. Mid-Sweden University.

Brown, S. D. (2002). Michel serres: science, translation and the logic of the parasite. Theory, Culture \& Society, 19 (3), 1-27.

Callon, M. (1986). Some elements of a sociality of Translation: domestication of the scallops and the fishermen of Saint Brieue bay, In J. Law (Ed.) Power, action, and belief: A new sociology of Knowledge? (PP. 196-233). London: Routledge and kegan Paul.

Callon, M. (1986a). The Sociology of an Actor-Network: The Case of the Electric Vehicle Mapping the Dynamics of Science and Technology.

Contractor, N. S., Monge, P. R., \& Leonardi, P. M. (2011). Multidimensional networks and the dynamics of sociomateriality: Bringing technology inside the network. International Journal of Communication, 5, 682-720.

Custers, (2012). Technology in Policy; Experiences, Obstacles and Police needs. Computer Law \& Computer Law \& Security Review.

Danielson, U. (2007). Relationships Between Information Communication Technology and Psychosocial Life Environment. Students and Young Urban Knowledge Workers in the ICT-Era. Mid Sweden Doctoral Thesis 41.

Earl, (1991). Information Infrastructure, Structure, Properties and process.

ERP systems, and data warehouse to help facilitate an organization's knowledge discovery process (Acs, Carlsson, \& Karlsson, 1999; Wickramasinghe, 2005).

Fenwick, T., \& Edwards, R. (2010). Actor-network theory in education. New York: Routledge.

Hanseth, O. (2004b). From systems and tools to networks and infrastructures - from design to cultivation. Towards a theory of ICT solutions and its design methodology implications., Manuscript

Heeks, R., (2003). Causes of E-Government Success and Failure [Homepage of IDPM.

Hussey, J., \& Hussey, R. (1997). Business research, New York: Palgrave.

Kroenke, D M. (2008). Experiencing MIS. Prentice-Hall, Upper Saddle River, NJ Macmillan Press, London: 19-34.

Micky \& Brookway (1989). IT infrastructure as the enabling tool - document marketing online. Monteiro (2013). Information Infrastructure: Boundaries, Ecologies, multiplicity. Online Business Dictionary (2017).

Ovass Shafi (2010). Images for software suites www.ovass.com. 
Pironti (2006). Information Infrastructure Design to support Home Uppsala, University.

Ssewanyana, J. \& Busler, M., (2007). Adoption and usage of ICT in developing countries: case of Ugandan firms. International Journal of Education and Development using Information and 81 Communication Technology, 3 (3), 49 - 59. Available at: http://ijedict.dec.uwi.edu/inc University of Manchester], [Online]. Available: http://www.e-devexcha nge.org/eGov/causefactor.htm [23.07. 2013].

Yan, S. Tu, Y.P. (2002). A network model for airline cabin crew scheduling. European Journal of Operational Research, 140(3), 2002, 531-540

Yan, S. Tseng, C. H. (2001). A passenger demand model for airline flight scheduling and fleet routing. Computers \& Operations Research, 29(11), 1559-1581 